\title{
CAJA DE RESONANCIA. EL PATIO DE LA CASA MMI DE SOSTRES
}

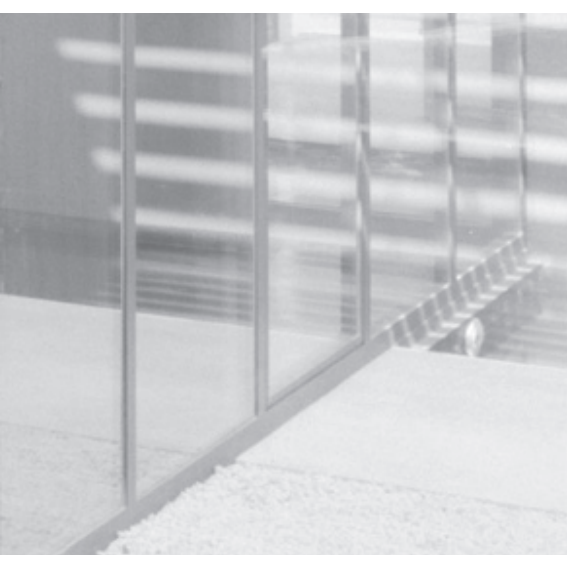

Sonia Vázquez Díaz

Resonance box. The courtyard in the MMI House by Sostres

Boletín Académico. Revista de investigación y arquitectura contemporánea

Escuela Técnica Superior de Arquitectura. Universidade da Coruña

elSSN 2173-6723

wuw.boletinacademico.com

Número 5 (2015)

Páginas 39-50

Fecha de recepción 02.11.2014

Fecha de aceptación 08.01.2015

https://doi.org/10.17979/bac.2015.5.0.1037

\section{Resumen}

Buscando el distanciamiento radical de la tradición, el patio de la casa MMI se despoja de todo elemento orgánico y renuncia a establecer relaciones visuales tanto con el espacio exterior como entre ámbitos interiores de la casa. Este drástico ensimismamiento resulta aún enigmático para algunos críticos. A través del análisis espacial y perceptivo, en este artículo se exploran los resultados de este hermetismo: alcanzar las máximas cotas de abstracción y preservar la percepción de los fenómenos estéticos más sutiles.

\section{Abstract}

The courtyard of the MMI House is deprived of vegetation. Any visual relationship, both between the inside and outside and among different interior areas is avoided. Its configuration is radically and deliberately distanced from the traditional. This drastic closure remains baffling for some critics. Using spatial and perceptual analysis, this paper explores the outcomes of the courtyard isolation: achieving the maximum degree of abstraction and allowing us to perceive the subtlest aesthetic phenomena.

\section{Palabras clave}

Percepción del espacio, Apreciación estética, Abstracción, Sostres, Casa MMI

\section{Keywords}

Spatial perception, Aesthetic appraisal, Abstraction, Sostres, MMI House 


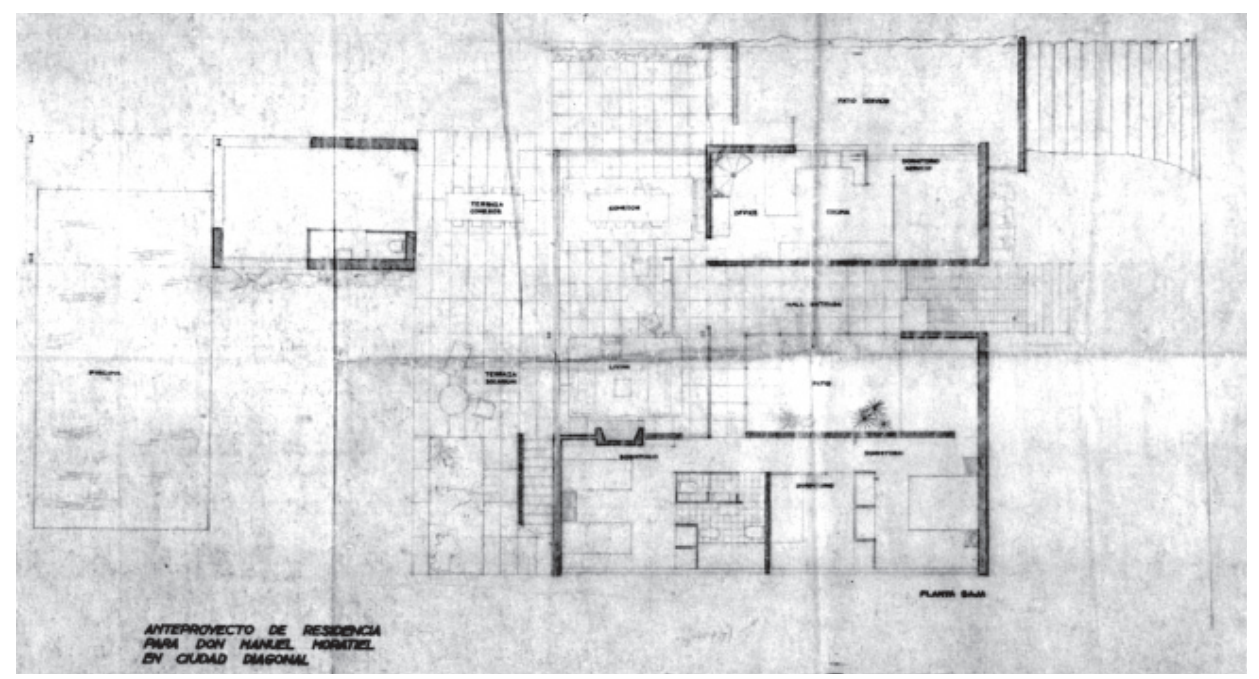

01 Planta del segundo anteproyecto de la casa MMl (febrero de 1956)

\section{INTRODUCCIÓN}

José María Sostres construye entre 1956 y 1957 una segunda residencia para Manuel Moratiel Iban en Ciudad Diagonal, Barcelona, manifestando claramente en la memoria del proyecto su voluntad de explorar a través de ella el concepto de patio desde un planteamiento moderno, despojado de sus connotaciones tradicionales ${ }^{1}$.

Comienza planteando dos anteproyectos, ambos fechados en febrero de 1956. El primero es una propuesta sin patio, deudora de la casa $\operatorname{Iranzo}^{2}$, de la que se conservan en el archivo del arquitecto escasos bocetos previos, dos plantas completamente resueltas sin referencia a su ubicación, y una perspectiva inacabada; y que será abandonada ${ }^{3}$. El segundo anteproyecto, que será el definitivo, cuenta con mucha más documentación ${ }^{4}$ : plantas en las que se esboza el encuentro con los límites de la parcela, dos perspectivas mucho más trabajadas y numerosos bocetos. En esta segunda opción el programa se compacta y pasa a articularse alrededor de un patio que llega hasta fachada: en su mayor parte se abre al cielo, con una pequeña franja pavimentada y el resto tapizado por vegetación, mientras que en la zona adyacente al dormitorio se dispone una pérgola, generando así un espacio intermedio ${ }^{5}$ (Fig. 01).

En el proyecto definitivo, que data de marzo de 1956, el patio se reduce y la zona pergolada es colonizada por un ámbito secundario del dormitorio principal; se dispone en él un estanque con plantas acuáticas y se pavimenta casi por completo, dejando el espacio estrictamente necesario para que crezca un pequeño árbol y unas trepadoras para tapizar el fondo del patio. Tanto en la planta como en la sección los vidrios van de suelo a techo, permitiendo la franca comunicación visual entre vestíbulo, salón y el ámbito del dormitorio $^{6}$ (Fig. 02).

Sin embargo, durante las obras, Sostres elimina la vegetación del patio, lo cubre con lamas y lo escinde por completo del dormitorio, renunciando a la transparencia fenomenológica inicialmente anunciada ${ }^{7}$ (Fig. 03). El resultado es un patio completamente interiorizado y volcado sobre sí mismo; un patio sin cielo, deliberadamente vacío, formalizado tan solo por planos desnudos con diferentes colores y texturas. Un patio para ser contemplado, pero no habitado.

Atendiendo a lo que el propio Sostres escribe, éste considera el patio como tema fundamental de la obra $^{8}$. Sin embargo, la desnudez y ensimismamiento del patio parece resultar desconcertante para algunos críticos, ya que cuando escriben sobre la casa MMI apenas se ocupan de él, desplazándolo a una condición marginal o anecdótica. Juan José Lahuerta sólo le dedica un párrafo en su extenso artículo en Casabella ${ }^{9}$, mientras que en AV Monografías apenas se menciona $^{10}$. Para Carme Rodríguez y Jorge Torres, la Moratiel no puede considerarse una casa-patio, ya que éste «no es el elemento fundamental de la composición, sino que parece relegado a una entrada de luz y aire o a un juego de diafragmas, transparencias y claroscuros ${ }^{11}$, y en términos semejantes se refieren a él en la revista $2 \mathrm{C}^{12}$. 


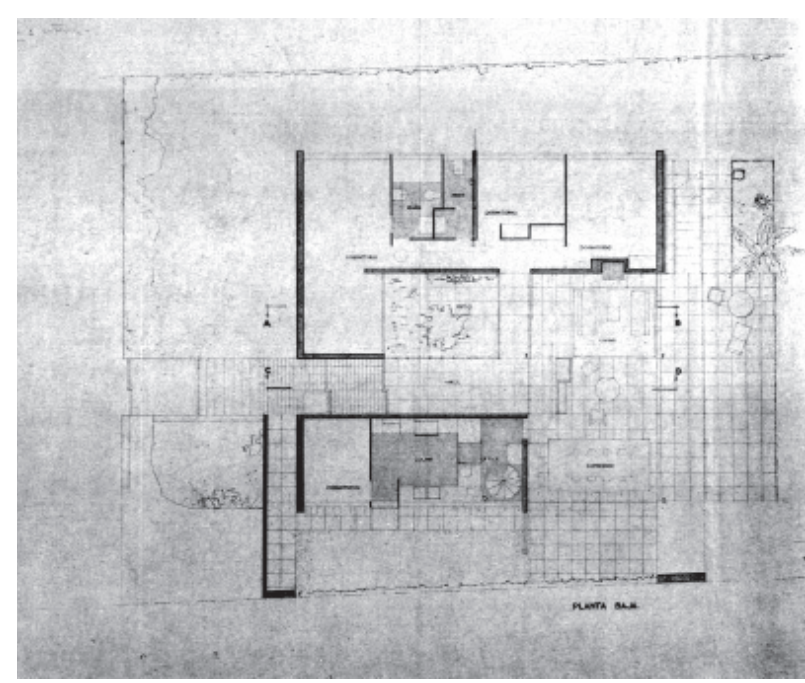

02 Planta de proyecto de la casa MMI (marzo de 1956) 03 Planta construida de la casa MMI (fin de obra: 16 de marzo de 1957)

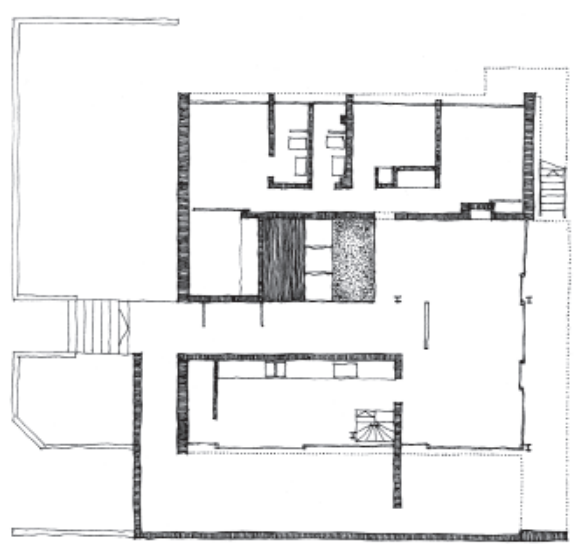

Antonio Armesto, inicialmente, no lo considera relevante en su tesis, ya que casi no repara en él ${ }^{13}$, pero en publicaciones posteriores va, paulatinamente, prestándole más atención ${ }^{14}$. En el análisis que elabora con Claudia Liberatore, se detiene en su excepcional valor perceptivo ${ }^{15}$; no obstante, manifiesta su extrañeza ante la decisión de eliminar la comunicación visual entre el patio y el dormitorio ${ }^{16}$, ya que de mantenerse la apertura inicialmente proyectada, éste «se abriría a una rica transparencia a través del patio, hacia el jardín ${ }^{17}$.

El patio, totalmente ajeno a la convención, tampoco es apreciado por los herederos del Sr. Moratiel que en 1984, en el transcurso de las obras de remodelación que encargan a Joan Bassegoda Nonell, deciden transformarlo en un aseo ${ }^{18}$. Afortunadamente, la casa fue fielmente reconstruida por el arquitecto Joan Roig para vivienda propia ${ }^{19}$, quien sin embargo no resistió la tentación de ocupar el patio con macetas y una escultura ${ }^{20}$.

La radical clausura y vacuidad del patio resulta perturbadora, en mayor o menor grado, tanto para los propietarios como para los arquitectos que se han enfrentado a la obra, sea como profesionales o como críticos. No es posible conocer de manera fehaciente las razones o reflexiones que llevaron a Sostres a tomar estas decisiones durante la obra; en el Fondo A. Sostres se conservan dos croquis con dos bocetos en perspectiva que estudian la percepción del patio desde el acceso, poniendo especial énfasis en el impacto visual del volumen del estudio situado en la cubierta, así como la sucesión de diafragmas transparentes que velan la visión del jardín ${ }^{21}$ (Fig. 04). Al lado de uno de ellos, en trazos muy tenues, se intuye lo que podría interpretarse como la visión opuesta del patio $^{22}$; contrariamente a lo que se representa en la sección del proyecto (Fig. 05), el paño de vidrio que separa del dormitorio se sustituye por un paramento opaco que se rasga horizontalmente antes de alcanzar la cubierta (Fig. 06). Dado que no está fechado, no es posible conocer en qué momento del proyecto fue realizado, pero es un indicio de que el patio fue evolucionando progresivamente hacia una mayor clausura.

¿Es este paulatino ensimismamiento y despojamiento, cuestionado e incomprendido, una decisión acertada? ¿Qué se consigue con ello? Sostres, para quien la modestia es una virtud suprema ${ }^{23}$, escribe en la misma época en la que está desarrollando este proyecto el artículo "Creación arquitectónica y manierismo» ${ }^{24}$, donde además de manifestar que el objetivo de los arquitectos de su generación no ha de ser revolucionar, sino profundizar y llevar al límite la experiencia racionalista, declara que «la verdadera obra de arte nace de un acto selectivo de autolimitación, y éste es un buen camino para llegar a la perfección, en términos artísticos» ${ }^{25}$.

Plantamos, por tanto, la hipótesis de que el despojamiento del patio responde a un ejercicio de autolimitación de recursos, de renuncia deliberada a estímulos perceptivos potentes - tales como la transparencia fenomenológica, la visión del cielo o la disposición de vegetación-, en aras de alcanzar la máxima abstracción. El propósito de este artículo 


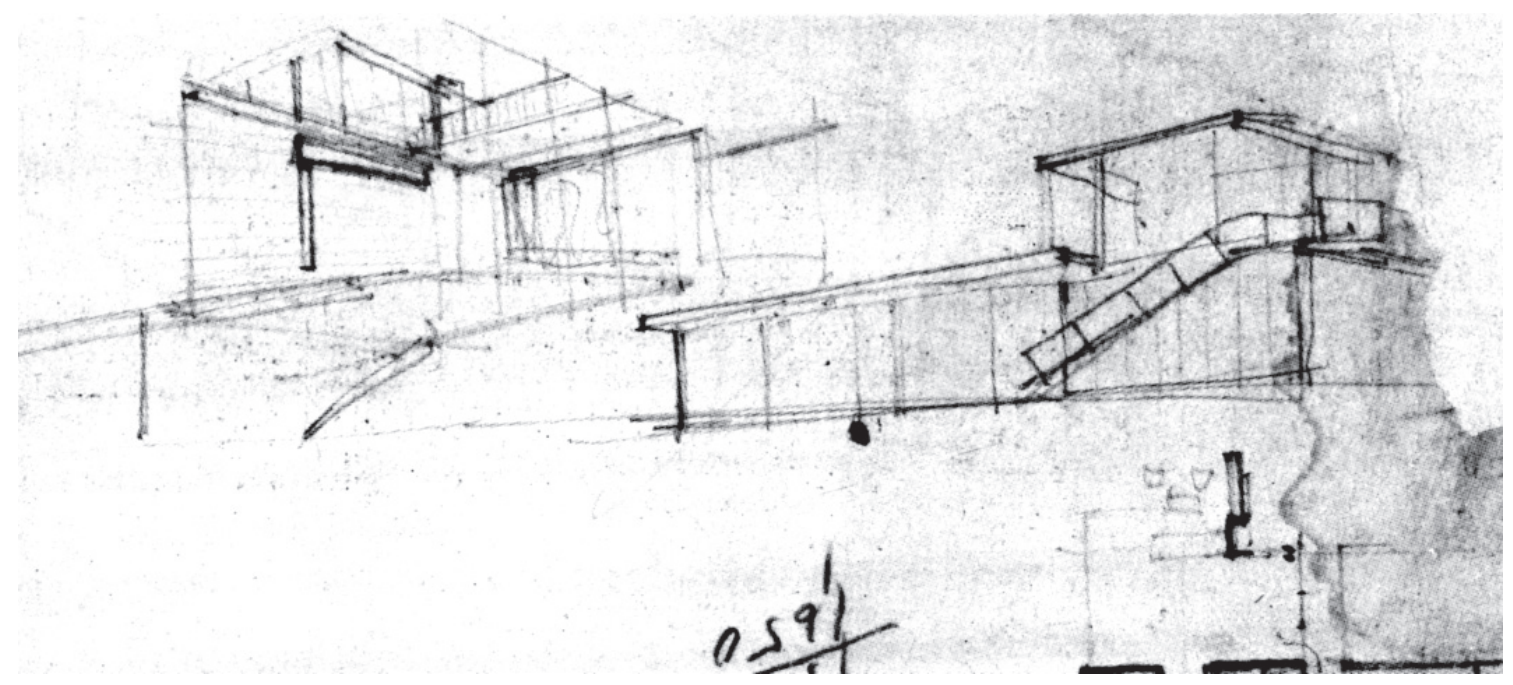

04 Boceto de José María Sostres donde se estudia la visión del patio desde el acceso (sin fecha)

es, por tanto, analizar las consecuencias espaciales y perceptivas del cambio introspectivo en la configuración del patio, para dilucidar si consigue - o no- evidenciar efectos sensoriales sutiles que hubiesen pasado desapercibidos, en caso de haberse mantenido su configuración inicial.

Para ello, se analizarán minuciosa y sistemáticamente un conjunto de documentos gráficos sobre el patio, tanto de la época como actuales, en la búsqueda de las emociones estéticas producidas en el habitante por su configuración final ${ }^{26}$.

\section{ESPACIALIDAD Y PERCEPCIÓN DEL PATIO}

Aunque el patio en la casa MMI ocupa una posición prácticamente central, se va descubriendo paulatinamente a medida que se avanza por el vestíbulo; se sitúa calladamente en un margen del recorrido, buscando recoger miradas laterales, distraídas. Al borde del camino constituido por el eje visual que atraviesa la casa, cuyo polo tensionador es la ancha visión de la ciudad con el mar al fondo, un pequeño recodo de belleza geométrica y desnuda se perfila inesperadamente (Fig. 07).

El patio es un exterior expuesto a la intemperie; sin embargo, a través de él no se perciben referencias del entorno, ni se disponen elementos vegetales que lo acerquen a la idea de paisaje controlado. Durante el transcurso de las obras, el patio esbozado en los planos de proyecto, descubierto y habitado por un árbol, se interiorizó completamente, manteniendo el estanque. Lo vivo y lo orgánico fue reemplazado por lo inerte e inorgánico.
Insólitamente, es un patio sin cielo. En la búsqueda de la abstracción de la idea de patio, en la determinación expresa del distanciamiento de lo folklórico, se renuncia radical y voluntariamente a todas las asociaciones conocidas y convencionales, a todo aquello que se espera encontrar en un patio doméstico mediterráneo.

Se vela el cielo mediante un dispositivo tectónico espacial, una pérgola de lamas que permite que la luz se deslice pero reteniendo la vista. Cuando el visitante se aproxima a ella, su opacidad visual se transmateriali$z a^{27}$ y pueden descubrirse retazos de cielo a través de sus intersticios.

$\mathrm{Al}$ atravesar las lamas, la luz se filtra perfilando una figura de tiras de luz que se dibuja sobre los paramentos opacos, que actúan como pantallas de proyección. La figura de luz va desplazándose por las distintas superficies a medida que pasa el tiempo y la posición aparente del sol va avanzando. La distinta textura y color de las superficies y la posición horizontal o vertical que ocupan logran una transfiguración gradual, indefectible, constante. Una parte puede estar sumergida en el fondo del estanque oscuro y entonces sus bordes son difusos y cimbreantes, meciéndose al pausado ritmo del agua. Al tiempo, otro fragmento puede proyectarse sobre el paramento rojizo, y así la luz absorbe parte de esa tonalidad cálida, transmitiéndola a la atmósfera de la casa. Si las tiras de luz impactan sobre la grava, los bordes de la figura se fragmentan y desdibujan, y la luz rebota en diversas direcciones gracias a las múltiples facetas de los minúsculos prismas irregulares de mármol, haciéndose más difusa. Cuando la figura de 

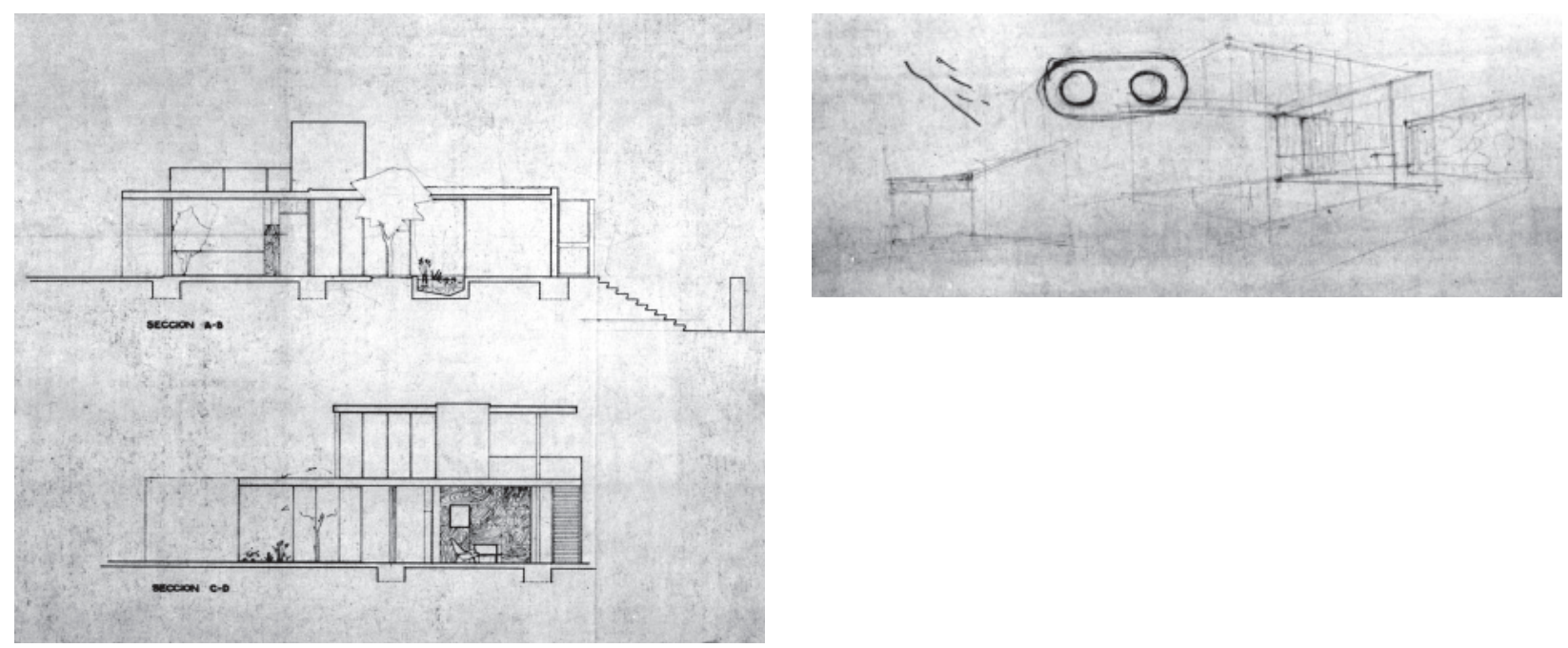

$\mathbf{0 5}$ Secciones de proyecto de la casa MMl

06 Bocetos de José María Sostres en los que se ensaya la percepción del patio desde el acceso y la visión opuesta, desde el salón (sin fecha)

luz se desplaza por los paramentos verticales blancos, la luminosidad del ambiente se multiplica, especialmente cuando el sol alcanza el cénit.

La figura de tiras de luz va acariciando las distintas superficies de la casa, transformándose con su contacto, absorbiendo sus especificidades.

La proyección de la figura de luz sobre la pared, la grava, el pavimento de hormigón y el estanque genera un entramado de direcciones contrapuestas. Al incidir el sol sobre las lamas, la luz se filtra creando un patrón de tiras paralelas de luz y sombra, cuyo ángulo depende de la posición del sol en cada momento. Pero las propias lamas, de color blanco, reflejan la luz en la dirección contraria. De este modo, cada lama proyecta un haz de sombra en una dirección y un haz de luz en la opuesta, generando un entramado de luces y sombras superpuestas, entretejido según relaciones geométricas intrínsecamente interdependientes (Fig. 08).

La casa, cuya configuración se somete a la disciplina ortogonal, se viste con entramados cambiantes, caracterizados por la oblicuidad y la superposición de múltiples direcciones. En ocasiones también confluyen percepciones inesperadas, como cuando el sol proyecta su luz desde el suroeste y las tiras de luz se proyectan sobre el paramento blanco del patio. Entonces, el cilindro de la azotea arroja su sombra sobre el patio y los ecos de lo curvo resuenan en el territorio de lo rectilíneo (Fig. 09). Al mismo tiempo, una esquiva y enigmática figura de solo dos tiras de luz atraviesa el vestíbulo, resultado de la incidencia del sol sobre los paramentos de vidrio del estudio situado sobre la cubierta, que se proyectan en la dirección contraria (Fig. 09).

El tratamiento del pavimento del patio reafirma su carácter no estancial, su vocación de vacío para ser contemplado más allá de sus límites. Se resuelve mediante tres franjas de texturas muy diversas: la banda central, un pavimento de losas al mismo nivel del suelo, separa dos cavidades: un estanque de agua y un estanque de grava (Fig. 10).

En el estanque de grava se producen simultáneamente dos mecanismos perceptivos opuestos. Por un lado, un paralelismo material: el descubrimiento de la variedad en la unidad de un material que se caracteriza por su heterogeneidad intrínseca. La superficie de grava está conformada por multitud de pequeños fragmentos de mármol, morfológicamente singulares, pero también idénticos en su naturaleza, lo que favorece su lectura como una entidad única. Al mismo tiempo, en sentido contrario se puede describir un paralelismo perceptivo: la letanía visual. Es posible escrutar la acumulación de áridos para descubrir las infinitas y minúsculas variaciones de tamaño, color y forma que individualizan cada pieza, un modo de contemplación atenta que induce a la serenidad y la introspección, como ocurre en los jardines secos japoneses o karesansui ${ }^{28}$.

El vaso del estanque de agua se pinta de un color oscuro para producir la impresión de una profundidad insondable; en sus aguas sombrías vibran las tiras de 
07 Aparición lateral del patio respecto al recorrido de acceso

08 Entramado de tiras de luz proyectado sobre las distintas superficies de la casa

09 Una figura de solo dos tiras de luz atraviesa el vestíbulo, resultado de un reflejo inesperado en el vidrio del estudio sobre la cubierta. El cilindro arroja su sombra y los ecos de lo curvo se manifiestan en el territorio de lo rectilíneo

10 Proyección vibrante de la figura de luz reflejada por el estanque de agua
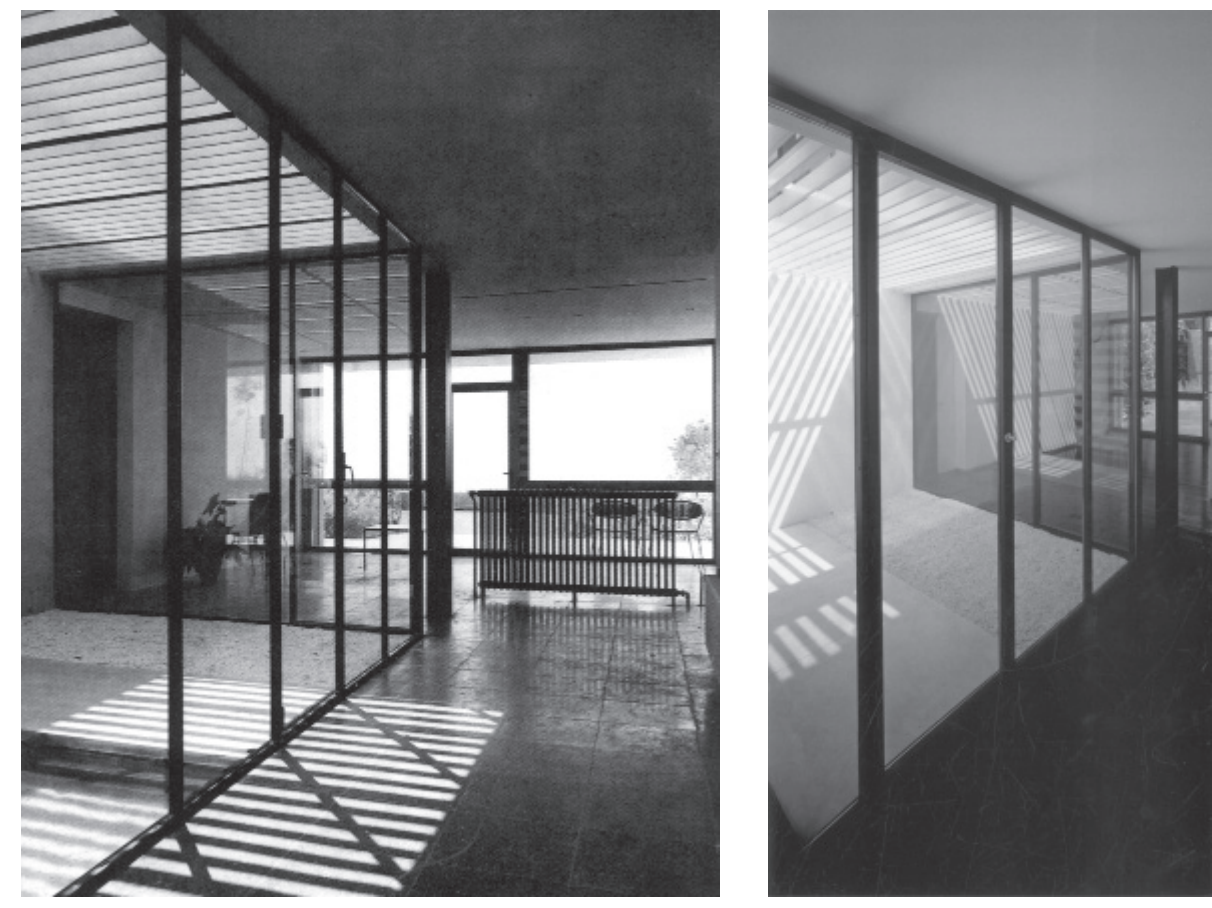
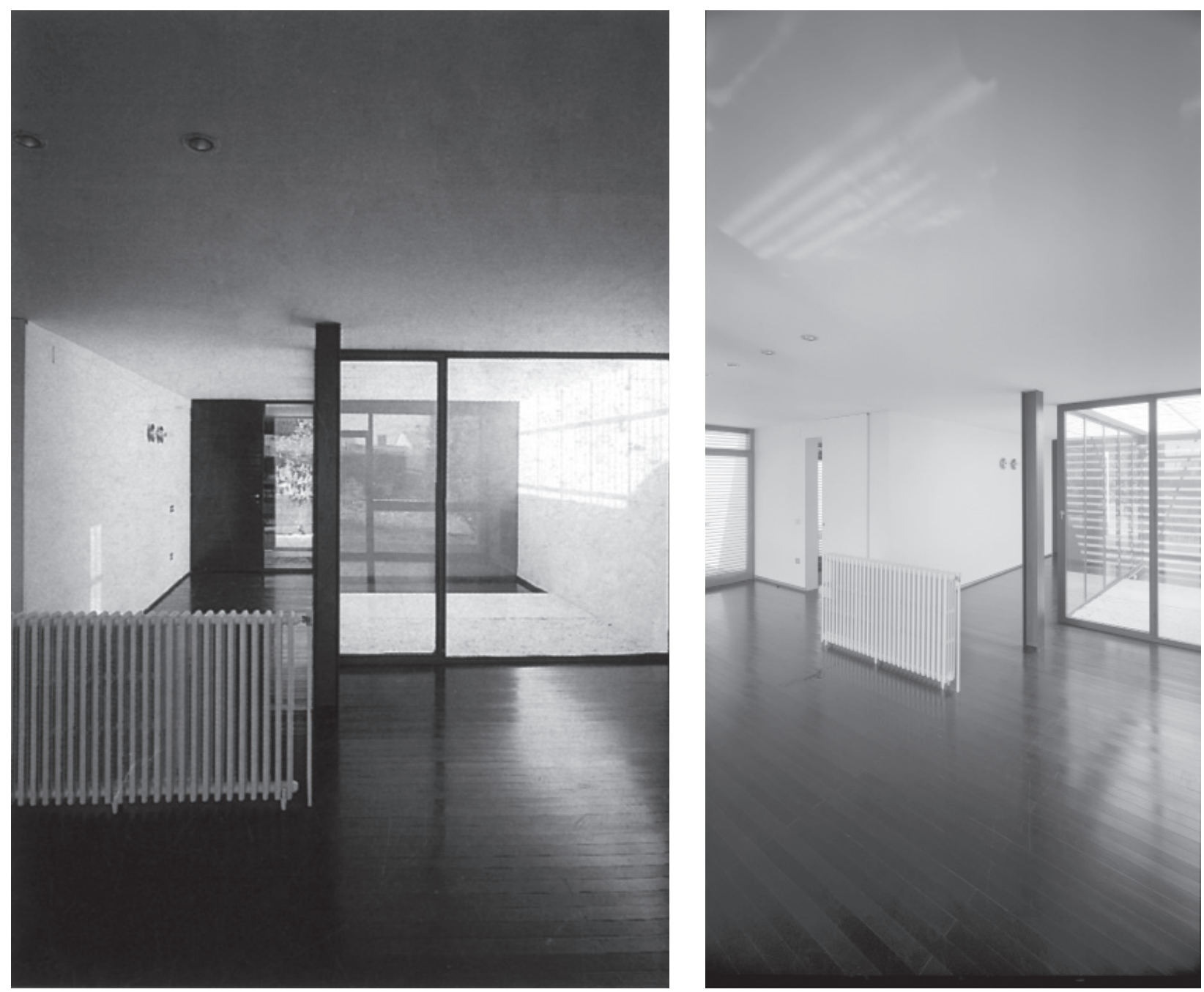
luz filtradas por las lamas, y en ocasiones la superficie proyecta su palpitación sobre el techo, permitiendo que lo móvil anide en lo inmóvil (Fig. 11).

A través del pavimento, un cúmulo de contrastes se evocan en el patio. Se pasa de la rugosidad de la grava a la tersura del pavimento apomazado, culminando la gradación con la textura líquida y reflectante del agua. Se opone la profundidad sugerida del estanque de grava con la profundidad evidente del estanque de agua, y a su vez, ambas con la banda enlosada, enrasada y superficial. Y se convoca un juego de gradación de consistencias: la compacidad del mármol y la disgregación de la grava, la fluidez densa del agua oscura y la fluidez ingrávida del aire (Fig. 12).

En coherencia con la morfología de plegaduras empleada en todo el proyecto, tanto en elementos constructivos como en ámbitos espaciales, los cerramientos del patio se configuran por conjunción de dos diedros, uno opaco y otro transparente.

Uno de los paramentos está pintado en el mismo color rojizo de la fachada, mientras que el otro mantiene el color blanco empleado en la tabiquería interior. El color oscuro del estanque y el rojizo del fondo del patio contrastan con el color blanco que predomina en el resto de superficies, asociándose para formar un nuevo diedro, esta vez en vertical. Al mismo tiempo, el color claro del estanque de grava y las losas en el suelo del patio destacan frente al color oscuro de los pavimentos interiores, especialmente el de la tarima actual, y se asocian perceptivamente a la pared blanca, formando otro diedro vertical que se engarza con el anterior (Fig. 13).

El diedro transparente está formado por vidrios de suelo a techo, montados sobre carpinterías de acero para reducir todo lo posible sus dimensiones y minimizar su impacto visual. De esta forma, la integración perceptiva del patio es máxima, al mismo tiempo que, paradójicamente, el carácter de lugar inaccesible sigue siendo patente. Los paramentos de vidrio buscan ser un velo etéreo para preservar el vacío; dado que las plegaduras caracterizan la morfología de la casa, la arista se dibuja nítidamente con la perfilería. El pliegue de vidrio, prácticamente inmaterial, se transmaterializa a través del reflejo: su transparencia se transforma en una semi-opacidad que vela la visión. Lo inmaterial se convierte en material ${ }^{29}$.

Los reflejos generan un juego de duplicidades entre la imagen real del objeto y la imagen irreal reflejada, que se muestra ambigua, de límites difusos y superponiéndose a lo real. Como en el caso de la transparencia fenomenológica propia del cubismo, definida por Rowe y Slutzky para el espacio arquitectónico, no se puede percibir la imagen real y la irreal simultáneamente, sino que se ha de decidir qué es el fondo y qué es la figura, fijando la atención alternativamente en lo ilusorio o en lo tangible ${ }^{30}$.

En el patio de la casa MMI, la imagen de lo situado a la espalda del observador se proyecta en el paramento de vidrio enfrentado a él; a su vez, se imbrica con el reflejo de lo adyacente en el paramento lateral y asimismo con la visión real del espacio contiguo, el salón (Fig. 14).

En ocasiones en el reflejo resuena lo real con una intensidad amortiguada, como un eco visual, mientras que en otras lo ilusorio es tan intenso que impide la visión de lo tangible, materializando el vidrio hasta el extremo de opacar su permeabilidad visual.

Se producen además ambivalencias perceptivas en el reflejo; lo horizontal se vuelve vertical cuando el vidrio se tiñe con la imagen del pavimento o de las lamas de la pérgola; y en el estanque, lo vertical se vuelve horizontal cuando refleja el rojo del paramento.

En el reflejo se revela lo oculto al atisbar desde el vestíbulo el ámbito aún no descubierto del comedor. Lo que no es arquitectura reverbera en la arquitectura, ya que el vidrio se empapa de la vegetación del jardín y del paisaje lejano.

En la MMI, el patio se refleja a sí mismo. No son la casa ni el entorno los que se miran en el patio, sino que su propia imagen se proyecta insistentemente, expandiéndose e invadiendo virtualmente en el espacio y duplicándo su profundidad aparente. Otras superficies de la casa redundan en el espejado del vacío, como el pavimento, el cortavientos o el cerramiento de vidrio del salón, donde el patio, una vez que se ha replicado a sí mismo en su propia membrana de vidrio, reverbera una segunda vez con una intensidad distante, atenuada. Como consecuencia de este mecanismo de autorreferencia, el color rojo, limitado en el interior al lateral menor del patio, impregna la atmósfera de la casa de calidez y vitalidad.

La reiteración tectónica espacial —la aliteración de elementos lineales separados por una distancia sistemática- es una constante en el proyecto: se encuentra presente en la estructura tubular del radiador, en 

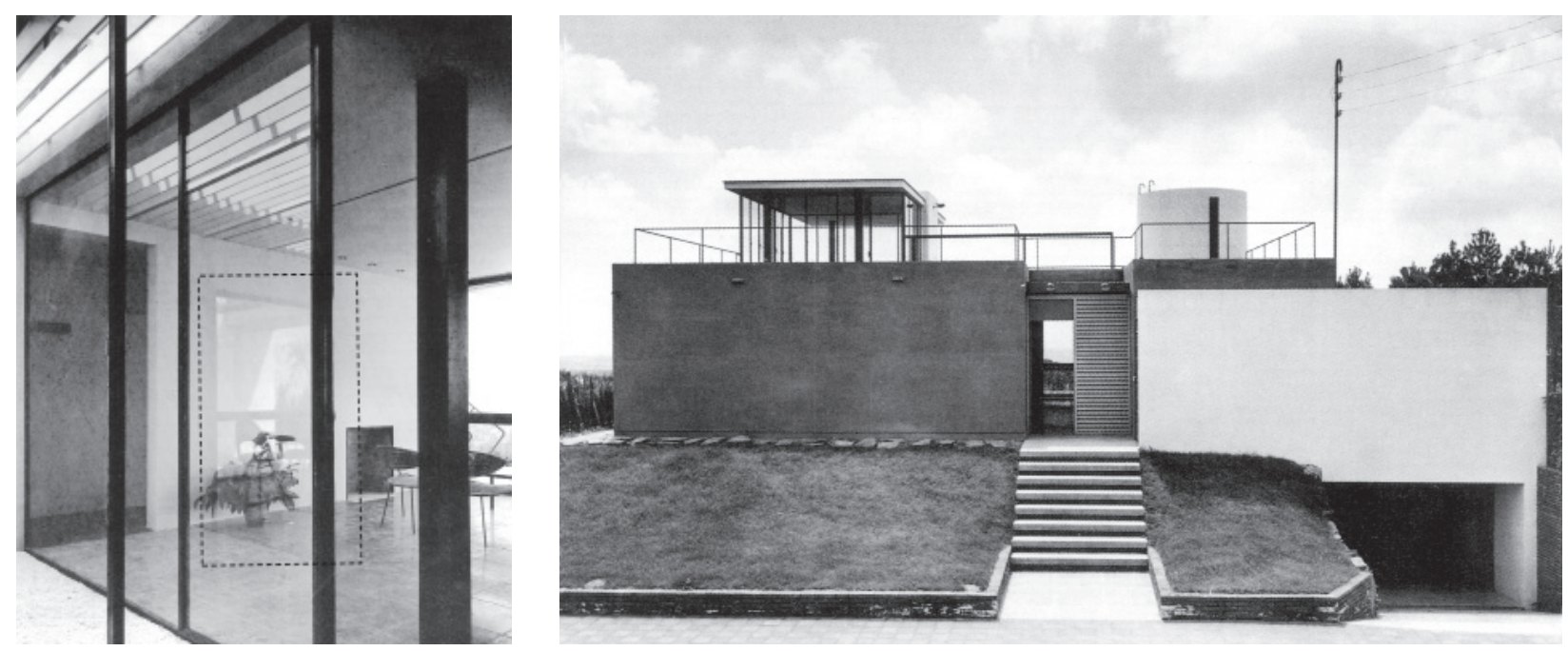

11 A través del reflejo, el ámbito del comedor se atisba antes de ser revelado 12 Rendija en fachada a través de la que se atisba el paisaje lejano

los peldaños sin tabica del acceso, en las persianas de librillo en el salón comedor o en la pérgola del patio, en la que las lamas se disponen a intervalos regulares $y$, cada cinco, aparece una lama de mayor espesor. Esta repetición de piezas longitudinales, cuyas dimensiones y separaciones encajan matemáticamente gracias a la modulación precisa que rige el proyecto, materializa la percepción de un ritmo.

El ritmo se define como la alternancia entre opuestos —entre sonido y silencio, entre lleno y vacío- que se suceden según un patrón determinado; así se estructura la totalidad, estableciendo ciclos o pautas que introducen un mayor o menor dinamismo. En este caso, la percepción del ritmo impreso por los elementos lineales se amplifica por medio de las sombras arrojadas y la conjunción de reflejos en los vidrios, el pavimento y el estanque. A su vez, la intercalación de vacíos entre los llenos alude al concepto de ligereza, que también resuena en otros elementos constructivos: la dimensión mínima de la perfilería de acero del patio, teñida de oscuro, los pilares de acero laminado o la insistencia en disminuir el canto visible de los planos horizontales de la cubierta.

\section{MÚSICA CALLADA RESONANDO EN EL VACÍO DEL PATIO}

La casa MMI ofrece a la calle una fachada hermética y abstracta, configurada por una composición de muros de color contrastado que se superponen plásticamente. Los planos se articulan, abriéndose entre ellos una pequeña hendidura a través de la que se anuncia una visión del paisaje lejano ${ }^{31}$.
La que inicialmente parece ser una casa-mirador, sin embargo, atesora en su interior un patio inesperado. La extrańeza es mayor en tanto que éste se distancia radicalmente de aquello que podría esperarse de un patio: no es una estancia al aire libre, no es un paisaje controlado, no es una ventana al cielo. Es un vacío capturado.

El patio se reduce a su esencia como cavidad que recoge el aire, la luz y el agua. Pero es la luz la que adquiere el protagonismo absoluto cuando, al filtrarse a través de las lamas, consuma un ritual que evoca la inexorabilidad del devenir ${ }^{32}$ : es «un meticuloso caleidoscopio que inserta en la casa el eje del tiempo» ${ }^{33}$.

La casa MMI puede entenderse como un instrumento de música callada, esto es, puramente visual, a la espera de ser tańido por la luz. Su caja de resonancia está cuidadosamente construida según reglas modulares que garantizan la estricta proporcionalidad, al igual que la afinación precisa permite que se despliegue toda la serie de armónicos que arropan a la nota fundamental emitida.

Los elementos compuestos por piezas longitudinales dispuestas a intervalos regulares materializan un ritmo visual constante, recurrente y marcado. Las láminas suspendidas de los peldańos del acceso introducen el tempo inicial de la pieza, que se subdivide y desdobla en los listones de la puerta de entrada. Una vez en el vestíbulo, los montantes de la carpintería y los tubos del radiador toman el relevo marcando el pulso. 


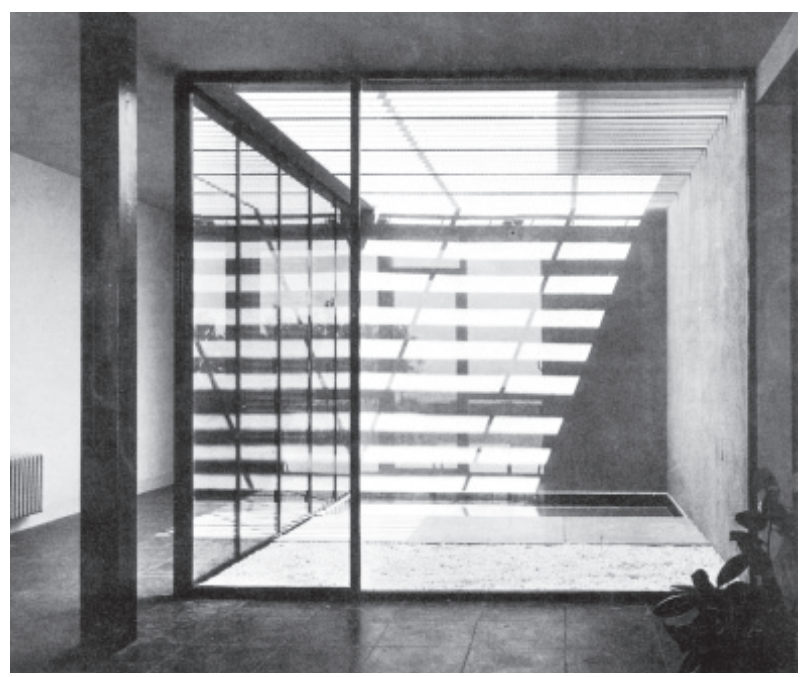

13 Los reflejos y sombras arrojadas multiplican el efecto de la figura de luz

Es la figura de luz la que traza la línea melódica que caracteriza la pieza: un motivo de estructura métrica acentuada, que alterna luz y sombra. La figura va acariciando las distintas superficies del patio, y así la cadencia se repite adquiriendo distintas texturas, tiñéndose de calidez, densidad o tersura. En ocasiones, se proyecta sobre una única superficie que la matiza, mientras que, en otros momentos, impregna diversos materiales que le infunden su temperamento, como si varias cuerdas interpretaran simultáneamente el mismo motivo melódico. Los reflejos en el vidrio y en el pavimento, en conjunción con las sombras arrojadas, multiplican el efecto sinfónico.

El motivo se repite, se transforma, evoluciona constantemente, sin perder su identidad; en algunos momentos emerge algún contrapunto inesperado, como la aparición de dos tiras de luz solitarias en la pared en sombra del vestíbulo, o el reflejo vibrante en el techo que ha rebotado en el estanque.

A través de una espacialidad imprevista, elevada a la máxima abstracción desde un rotundo distanciamiento del concepto de patio tradicional, Sostres nos propone entrar en contacto con el puro vacío, en el que resuenan las armonías del ritmo vital que acompasa el universo.

La música visual que entona la casa MMI, curiosamente, avanza conceptos que la música experimental empezaba a explorar en los mismos años de su construcción y que cristalizarán en la obra de La Monte Young, Steve Reich, Philip Glass o, más tarde, en la de Michael Nyman: «música basada en la continua repetición de un motivo, o breves figuras, normalmente diatónicas, en cuya interacción se van introduciendo lentos y graduales procesos de transformación, rítmica o armónica» ${ }^{34}$.

Es muy improbable que esta analogía sea una referencia consciente y buscada por el autor; sin embargo, demuestra su voluntad de búsqueda de la abstracción más radical, la sutileza y el refinamiento del resultado. También la conexión instintiva - como suele ocurrir con los maestros- entre la sensibilidad de Sostres y la vanguardia más experimental de la época. El propio arquitecto, al reflexionar sobre la relación entre Gaudí y las corrientes modernistas europeas, cree que se trata «más bien de una coincidencia en un mismo estado de espíritu, de captación de algo que flotaba en el ambiente de entonces, que no efecto de influencia por contacto directo» ${ }^{35}$.

\section{CONCLUSIONES}

A través del recorrido atento y el examen minucioso de todos los efectos perceptivos logrados por Sostres, se ha evidenciado la validez de la hipótesis inicial. La extrema interiorización del patio es indicio de la renuncia voluntaria a la multiplicidad de estímulos desde la conciencia de la fragilidad de los señuelos para atrapar emociones tan sutiles. Se prescinde de la visión del cielo para poder capturar la luz. Se desiste de la apertura del dormitorio principal al patio - como se recogía en el proyectopara impedir que la transparencia diluya la intensidad de la figura de tiras de luz. Así, el vacío se replica a sí mismo en los reflejos horizontales y verticales e invade 


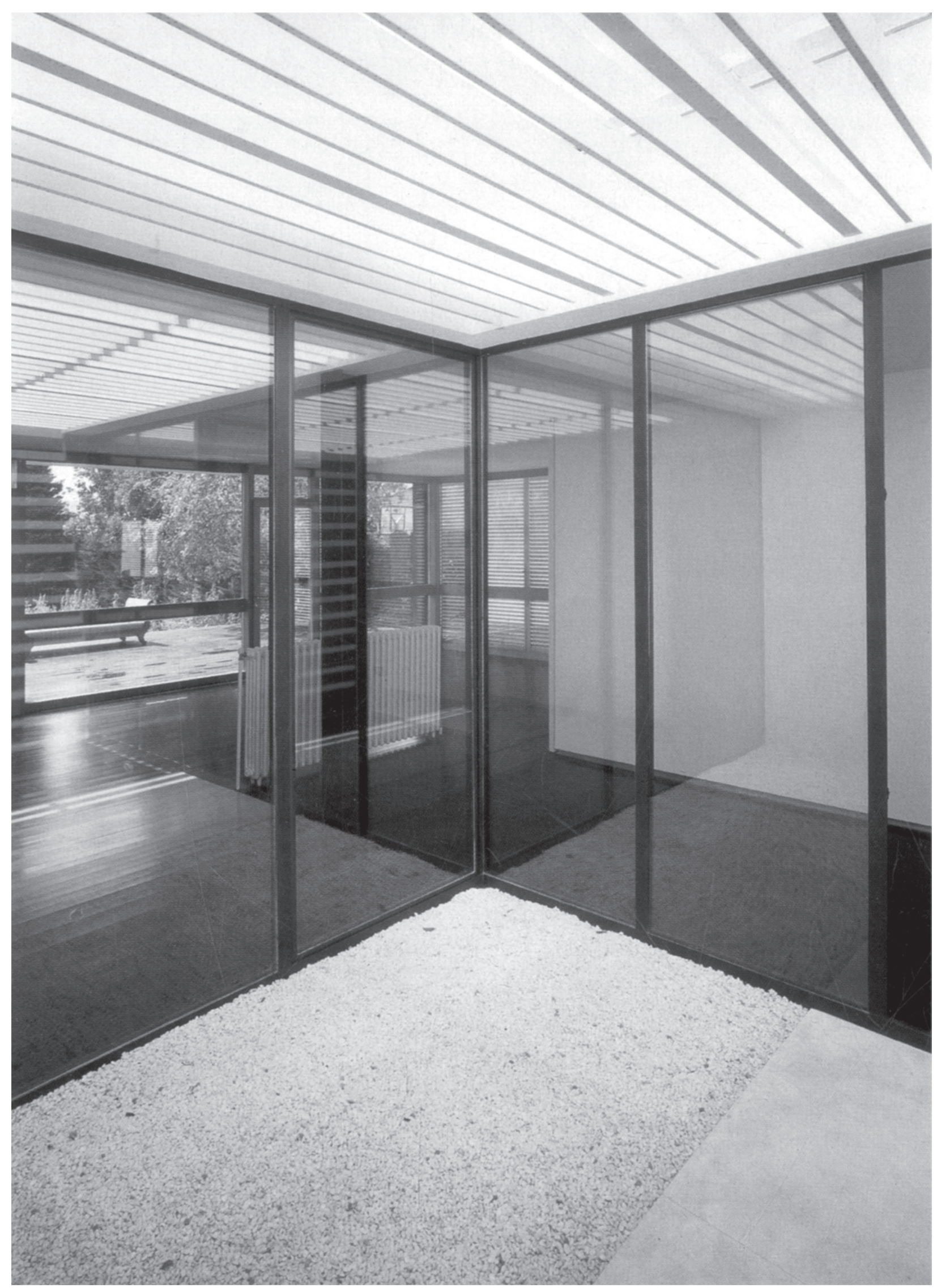

14 El patio activa el espacio interior de la casa, invadiéndolo con su reflejo 
el espacio de la casa, activándolo. Se suprime la vegetación para enfatizar la desocupación del espacio (Fig. 14).

Sostres va refinando la configuración del patio para lograr estos efectos perceptivos durante el periodo de obra, como parte final de un proceso proyectual en el que «juega más lo intuitivo y lo irracional que aquellas motivaciones que pudieran exponerse racionalmente, de manera aparentemente más precisa y concreta pero, en realidad, más errónea ${ }^{36}$ con objeto de cumplir la misión «de servir al hombre, tanto a las actividades prácticas de su existencia como a las espirituales y anímicas ${ }^{37}$.
Todos los cambios introducidos por Sostres respecto al proyecto redundaron en la depuración del patio como vacío, buscando la máxima abstracción para hacer de él una caja de resonancia donde, al evidenciar los más sutiles cambios en la cualidad de la luz y los patrones que forma, el instante presente se subraya y la poética del silencio se materializa a través de las huellas de la impermanencia. Conocer pormenorizadamente cómo operan las estrategias por él empleadas para dejar aflorar lo inefable, permite no solo apreciarlo en toda su intensidad, sino también tratar de infundirlo en los espacios que concebimos.

\section{Notas}

1 «En la composición se ensayó el tipo de casa con patio central, evitando en lo posible que tal elemento, tan seńaladamente mediterráneo, arrastrara al conjunto a una fácil sugestión folklórica» (José María Sostres Maluquer, «Casa M.M.I. en 'Ciudad Diagonal'», Cuadernos de arquitectura 33 (1958): 14).

2 Cf. Antonio Armesto Aira, «El aula sincrónica. Un ensayo sobre el análisis en arquitectura» (Tesis doctoral, Universitat Politècnica de Catalunya, 1993), 9.

3 Fondo A. Sostres - Archivo Histórico del COAC, Barcelona. También publicado en Juan José Lahuerta Alsina, Carles Muro Soler, Antonio Pizza de Nanno, Josep Quetglas Riusech et al., José María Sostres. Ciudad Diagonal (Barcelona: CRC Galería de Arquitectura, 1986), 62-65.

4 Fondo A. Sostres. También publicado en Lahuerta et al., Ciudad Diagonal, 66-69.

5 Armesto y Liberatore defienden que existe una indeterminación en la configuración del patio en este anteproyecto, ya que en su opinión, la zona pergolada parece formar parte del interior del dormitorio en la representación de la planta; sin embargo, en un examen detallado de ésta, puede verse que la separación entre esas dos zonas del patio es una sola línea, que indica un cambio de pavimento, en lugar de las dobles líneas que representan los vidrios que cierran el resto del patio. Es cierto que no se representa la puerta que comunica con el dormitorio, pero se debe a que se ha tomado la determinación de no representar ninguna puerta en toda la planta. Cf. Antonio Armesto Aira y Claudia Liberatore, «Iranzo y Moratiel», en José María Sostres. Casas Iranzo y Moratiel: Barcelona, 1956 y 1957 (Pamplona: T6 Ediciones, 2006), 60, nota 11.

6 Fondo A. Sostres. También publicado en Lahuerta et al., Sostres. Ciudad Diagonal, 70-71 y 74.

7 Se entiende por transparencia fenomenológica la articulación compleja de ámbitos espaciales con entidad formal propia que se interpenetran, se enlazan o deslizan unos tras otros. En este caso se habría producido una superposición espacial, ya que habría sido posible percibir simultáneamente tres capas espaciales: vestíbulo, patio y dormitorio principal. Cf. Colin Rowe y Robert Slutzky, «Transparency: Literal and Phenomenal», Perspecta 8 (1963): 45-54.

8 Además de lo expresado en la memoria publicada en Cuadernos de Arquitectura (ver nota 1), la mayor parte del breve texto que escribió a petición del Grupo 2C, trata sobre el patio: «M.M.I. Estructura metálica reducida a unos elementos expresivos. Patio. Fachada, terraza, jardín. Escalera. [...] El elemento PATIO es un tema en el que un arquitecto piensa siempre, y que un día y otro acaba tratando específicamente. [...] [El patio racionalista] es una consecuencia natural de un planteamiento modular y de la idea de cubrimiento con una placa sobre pies derechos, con cerramiento libre perimetral. Un espacio dentro de un espacio. Un espacio dentro de un volumen» (José María Sostres Maluquer, «Sostres habla de su obra», en Sostres arquitecto, ed. Antonio Armesto y Carlos Martí Aris. Barcelona: Ministerio de Fomento y Colegio de Arquitectos de Catalunya, 1999; 66).

9 «El patio de la casa MMI, sombreado por las vigas de la pérgola, recoge sin duda alguna imágenes tomadas de Breuer (de la casa Clark, por ejemplo), en el momento en que se transforman en las de una urna que protegen las reliquias recogidas en el transcurso de un paseo a través del jardín de la arquitectura moderna, que expresa una despiadada interpretación del historicismo de la Glass House» (Juan José Lahuerta Alsina, "Josep María Sostres e il sogno americano", Casabella 690 (2001): 27).

10 «las áreas comunitarias y de circulaciones, [están] ambas iluminadas por un patio interior cubierto por una pérgola de lamas que no llega a romper el carácter compacto de la planta central» («Casa Moratiel, Barcelona, 1956-1957», AV Monografías 60 (1996): 10).

11 Cf. Carme Rodríguez Pedret y Jorge Torres Cueco, Grup R (Barcelona: Gustavo Gili, 1994$), 90$.

12 «No nos atreveríamos a remitir esta vivienda a la tipología de casas con patio puesto que ni en el aspecto distributivo ni en el uso del elemento aparece caracterizada como tal. Así parece confirmarlo el modo en que ha sido reducido casi a una abstracción de sí mismo», en 2 C Construcción de la ciudad 4 (1975): 37.

13 «El patio resulta ya innecesario para su orden distributivo, quedando como un elemento de enriquecimiento espacial y lumínico» (Armesto, «Aula sincrónica», 11), aunque en la página 15 lo reconoce como "germen espacial».

14 Lo califica como un «volumen convexo lleno de sombras» en Armesto y Martí, Sostres arquitecto, 142. Más tarde, escribe: «El pequeño patio, finalmente, no es otra cosa que una máquina de inversión topológica que confunde la percepción de lo cóncavo y lo convexo, vaciando, de forma efectiva, el lugar. En las nuevas fotos de Jordi Bernadó vemos que el jardín en que Sostres convirtiera la casa es un jardín de sombras proyectadas, de reflejos transparentes e infinitos que la misma luz desvanece y un caleidoscopio que compone fragmentos de arquitectura moderna» (Antonio Armesto Aira, «Mitos familiares. La casa Moratiel de Sostres en Barcelona», Arquitectura Viva 73 (2000): 25).

15 «Las cuatro caras del patio quedan [...] definidas por dos diedros, uno opaco y otro transparente. Sobre el primero se proyectarán las sombras lineales de las lamas y estas sombras serán reflejadas y reproducidas por el segundo. Al juego contribuye el agua del pequeño estanque, de modo que cotidianamente en el interior de la casa se repite el espectáculo, continuamente variado, de la superposición por transparencia de reflejos de sombras y sombras de reflejos» (Armesto y Liberatore, «Iranzo y Moratiel», 29). 
16 «El dormitorio principal, que en los dibujos de la planta del proyecto parecía que iba a abrirse al patio por un amplio ventanal, queda, al fin, clausurado por un tabique y excluido del disfrute de la visión del jardín a través del núcleo de la casa, según una decisión que nos resulta aún misteriosa» (Armesto y Liberatore, «Iranzo y Moratiel», 29).

17 Armesto y Liberatore, «Iranzo y Moratiel», 60, nota 11.

18 Cf. Joan Roig i Duran, «Note sulla ricostruzione della casa MMI», Casabella 690 (2001): 22.

19 Cf. Armesto, «Mitos familiares», 25.

20 Extremo comprobado en una visita personal a la casa realizada el día 8 de junio de 2013. También puede verse su estado actual en Joan Roig i Duran, «Casa Moratiel (MMI)», con acceso el 08/01/2015, http://www.redfundamentos.com/blog/es/obras/detalle-128/.

21 Fondo A. Sostres, Archivo Histórico del COAC. También publicado en Lahuerta et al., Sostres. Ciudad Diagonal, 57, 60.

22 Ibídem, 60

23 Cf. José María Sostres Maluquer, Opiniones sobre arquitectura (Murcia: Comisión de Cultura del Colegio Oficial de Aparejadores y Arquitectos Técnicos, 1983), 39.

24 Tanto Armesto como Carme Rodríguez y Jorge Torres afirman que este escrito, publicado en la revista Arquitectura Cuba en La Habana en marzo de 1956, está íntimamente ligado al proyecto de la casa Moratiel. Cf. Armesto, Sostres Arquitecto, 200; y Rodríguez y Torres, Grup R, 90.

25 Sostres, Opiniones sobre arquitectura, 65-66.

26 Cuando la casa Agustí fue totalmente remodelada sin respetar su concepción inicial, Sostres escribió: «Si queda el testimonio fotográfico se conservará en el futuro su apariencia fresca y nueva —en plena juventud-, tan difícil de conservar en un edificio que, en definitiva, estaba destinado a ser un ejemplo y, en este sentido, ya había cumplido su objetivo" (Sostres, Opiniones sobre arquitectura, 7-8).

27 «Decimos que el muro se transmaterializa cuando su materia, gracias a la idea y a su propia cualidad material, es capaz de generar mutaciones de las propiedades transparentes, translúcidas y opacas entre sí gracias a la luz y a la visión» (Jesús María Aparicio Guisado, El muro. Buenos Aires: Librería Técnica CP67, 2000; 211)

28 Cf. Fernando Espuelas Cid, El claro en el bosque: reflexiones sobre el vacío en arquitectura (Barcelona: Fundación Caja de Arquitectos, 1999$)$, 131.

29 Cf. Aparicio, El muro, 216

30 Cf. Rowe y Slutzky, «Transparency».

31 Sobre las tapias, sus rendijas y rejas, reflexiona Luis Barragán: «Tal vez su belleza consiste en el aumento de importancia que dan a los espacios que protegen, dándoles además el fascinante atractivo de las cosas prohibidas" (Luis Barragán Morfín, Luis Barragán, Escritos y conversaciones. Madrid: El Croquis, 2000; 15-16).

32 «El cambio de color de la luz natural es una referencia que nos introduce en la dimensión temporal». Elisa Valero Ramos, La materia intangible: reflexiones sobre la luz en el proyecto de arquitectura (Valencia: Ediciones Generales de la Construcción, 2004), 19.

33 Cf. Armesto y Liberatore, "Iranzo y Moratiel», 29.

34 Mariona Sagarra i Trias y Joaquín Turina Gómez, «De lo menos lo mejor», en Less is more, eds. Vittorio Savi y Josep María Montaner Martorell (Barcelona: Col.legi d'Arquitectes de Catalunya/Actar, 1996), 134.

35 Cf. Sostres, Opiniones sobre arquitectura, 16.

36 Cita de Sostres recogida por Simona Pierini, «Entre líneas. Notas sobre algunos apuntes de Sostres», en Armesto y Martí, Sostres Arquitecte, 36.

37 Cf. Sostres, Opiniones sobre arquitectura, 33.

\section{Procedencia de las ilustraciones}

Fig. 01-06. Fondo A. Sostres. Archivo Histórico del COAC, Barcelona.

Fig. 03. Dibujo de la autora.

Fig. 07 y 11-13. Francesc Catalá-Roca (1958), Fondo Fotográfico F. Català-Roca - Archivo Fotográfico del Archivo Histórico del COAC.

Fig. 08. Jordi Bernadó, en Casabella 65/690 (2001): 20.

Fig. 09. Jordi Bernadó, en Arquitectura Viva 73 (2000): 25

Fig. 10. Jordi Bernadó, Archivo Fotográfico de Jordi Bernadó.

Fig. 14. Jordi Bernadó, en Arquitectura COAM Fundamentos 364 (2012): 45.

\section{Sobre la autora}

Sonia Vázquez-Díaz. Doctora Arquitecta y Máster en Urbanismo por la Escuela Técnica Superior de Arquitectura de A Coruña. Autora de la tesis Patios del silencio, dirigida por el Prof. Dr. Miguel Ángel Alonso del Val y el Prof. Dr. Luis Suárez Mansilla, de la Universidad de Navarra, y calificada Cum Laude. Profesora de proyectos en el Departamento de Proyectos Arquitectónicos y Urbanismo de la Universidade da Coruña. Profesora invitada en el Máster en Diseńo Arquitectónico de la Pontificia Universidad Católica Madre y Maestra de la República Dominicana. Como arquitecta del Estudio Zara (INDITEX) construyó tiendas en 12 países, entre las que destaca la rehabilitación de los restos de la iglesia de San Antonio el Real en Salamanca.

sonia.vazquez.diaz@udc.es 